\title{
Evolving local climate adaptation strategies: incorporating influences of socio-economic stress
}

Mattias Hjerpe and Erik Glaas

\section{Linköping University Post Print}

N.B.: When citing this work, cite the original article.

The original publication is available at www.springerlink.com:

Mattias Hjerpe and Erik Glaas, Evolving local climate adaptation strategies: incorporating influences of socio-economic stress, 2012, Mitigation and Adaptation Strategies for Global Change, (17), 5, 471-486.

http://dx.doi.org/10.1007/s11027-011-9337-3

Copyright: Springer Verlag (Germany) http://www.springerlink.com/

Postprint available at: Linköping University Electronic Press

http://urn.kb.se/resolve?urn=urn:nbn:se:liu:diva-77394 


\title{
Evolving local climate adaptation strategies: Incorporating
}

\section{influences of socio-economic stress}

\author{
Mattias Hjerpe \& Erik Glaas
}

Centre for Climate Science and Policy Research and Water and Environmental Studies Department for Thematic Studies, Linköping University, Nya Kåkenhus, SE-601 74 Norrköping, Sweden e-mail: mattias.hjerpe@liu.se

\section{Abstract}

Socio-economic and climatic stresses affect local communities' vulnerability to flooding. Better incorporation of socio-economic stress in local vulnerability assessments is important when planning for climate adaptation. This is rarely done due to insufficient understanding of their interaction, in both theory and practice. The omission leads to critical weaknesses in local adaptation strategies. This study analyses how socioeconomic stress interacts with climatic stress and shape local vulnerability to flooding, and how such stress can be more efficiently managed within local government organisations. A framework containing potential stresses was developed and applied to investigate how socio-economic stress affected exposure, sensitivity, and adaptive capacity in two case studies, using interview and group exercise transcripts. Cases consisted of major development projects in two Swedish municipalities, Gothenburg and Lilla Edet. The cases were similarly exposed to climatic stress but differed in socio- 
economic context, and previous professional climate change experience. Fierce foreign competition and market structure were seen as the two most significant socio-economic stresses influencing local vulnerability to flooding through shaping the 'local' worldview. In falling order sensitivity, exposure, and adaptive capacity were seen to be influenced by the socio-economic stresses. Two approaches to efficiently incorporate climatic and socio-economic stress in local management are proposed: shifting the focus of vulnerability assessments towards future sensitivity of people and settlements, rather than on the current infrastructure's sensitivity, would facilitate their use in planning and by 'mainstreaming' adaptation into long-term strategic planning vulnerability would be more dynamically addressed and periodically revised.

Keywords Adaptation strategies . Climate vulnerability . Flooding . Local government . Multiple stresses . Socio-economic stress

\section{Introduction}

Research on the human dimensions studies of global change have clearly demonstrated that processes influencing local vulnerability to climate variation and change are inherently dynamic, and shaped by both climatic and socio-economic stress (Adger et al. 2007; Bouwer et al. 2010). In practice, however, the socio-economic context is seldom explicitly considered, neither in local assessments of vulnerability to climate change nor in local climate adaptation strategies (O'Brien and Leichenko 2000; Füssel and Klein 2006). As argued by Preston et al (2010) improper reflection of stresses and the capacity to adapt to change are causing critical weaknesses when planning for climate adaptation. 
For example management practises often take the form of reactive and sector-based responses, diminishing the prospects to evolve more comprehensive climate adaptation strategies (Næss et al. 2005; Glaas et al. 2010; O’Brien and Hochachka 2010) or to better integrate climate adaptation into other policy areas (Huq and Reid 2004; Ahmad 2009; Biesbrook et al. 2010; Storbjörk 2010).

In striving to better understand the balance between socially, naturally and economically oriented stressors, scholars have paid considerable attention to the integrated vulnerability perspective. Integrated vulnerability is here conceived as a function of three interlinked components: exposure, sensitivity, and adaptive capacity (e.g., Adger and Vincent 2005; Adger 2006; Gallopin 2006; Urwin and Jordan 2007). This tripartite division provides a structure for analysing the influence of different types of stress. Since the interplay between socio-economic and climatic stress is an under-studied area, there is still no universally applicable technique developed for how to include such multiple stressors in assessments of local climate vulnerability or when developing local climate adaptation strategies. Previous studies have primarily focused on pin-pointing how specific socio-economic stresses are influencing local climate vulnerability, particularly in agricultural settings and for private rather than public actors (e,g, . Leichenko and O'Brien 2002; O'Brien et al. 2004; Eakin 2005; Belliveau et al. 2006; Keskitalo 2008a).

To forward the understanding of multiple stressors, this study aims at analysing how socio-economic stress interact with climatic stress and shape local vulnerability to flooding, and how such stress can be more efficiently managed within local government 
organisations. A conceptual framework, adapted from studies addressing how global economic and environmental changes inflict on local vulnerability, was developed to investigate how socio-economic stress affected the three elements of integrated vulnerability. Specifically, the framework was applied to two case studies consisting of major development projects within two Swedish municipalities, Gothenburg and Lilla Edet. Both cases are relatively highly exposed climatic stress (SOU 2007:60), but differ in their socio-economic context such as population, socio-economic structure, and previous professional experience of climate change. The scope of the article is further delimited by specifically addressing flood risks, which is one of the most alarming risks facing both cases. The data consist of notes and transcripts from twenty individual interviews and two group exercises with officials from municipal departments and local offices of national government agencies working with these projects. The following research questions have been central to the study:

1. What socio-economic stresses are perceived to be the most critical in shaping local vulnerability to flooding?

2. What specific elements of integrated vulnerability are influenced by the socioeconomic stress in the two municipalities?

3. How can climatic and socio-economic stress be more efficiently managed within local government organisations?

The paper is structured as follows. Section 2 describes the case studies and how the empirical material was collected and analysed. Section 3 presents the conceptual 
framework. Section 4 contains the main findings from the interviews and group exercises in the two cases. It evaluates how socio-economic stresses were seen to shape local vulnerability to flooding. Section 5 discusses how to better incorporate socio-economic and climatic stresses into local adaptation strategies. Section 6 concludes.

\section{Case studies and data collection}

\subsection{Case studies}

Both municipalities, Gothenburg and Lilla Edet, are located in south-west Sweden and were chosen because their flood risks are similarly stressed by climate variation and change due to their location along the river Göta älv. Climate change scenarios for the area indicate future aggravation of flood risks because of sea level rise and up to $30 \%$ more precipitation (Andersson-Sköld et al. 2008).

Despite sharing similar climatic stress, the two municipalities differ significantly in their socio-economic context (population, economic growth and structure) as well as in previous experience of working with climate change adaptation. Gothenburg, the second largest city in Sweden in terms of population (pop. 507,330 in December 2009, Statistics Sweden 2010), is the capital of the West Sweden region located at the Göta Älv outlet into Skagerrak. The city has a history of flooding due to the exposed location. It harbours the heart of the Swedish vehicle manufacturing, both local and regional government, and a growing tourist and visitor sector. Gothenburg encompasses dense settlements, several industrial sites, and main transport routes. In a national context, Gothenburg is increasingly seen as a spearhead in working with local responses to climate variation and change (see Glaas et al. 2010). For example Gothenburg was one of the first 
municipalities already in year 2004 to mandate departments and agencies to assess future impacts of extreme weather events in the light of climate change (Gothenburg 2006, 2009).

Described as a typical mill town, Lilla Edet (pop. 12,773 in December 2009, Statistics Sweden 2010) holds a remote location in the West Sweden region, situated $55 \mathrm{~km}$ upstream from Gothenburg along the river Göta Älv. Its low economic diversification, dominated by one private employer and the local government, is typical to other small Swedish municipalities. During the last fifty years, Lilla Edet has experienced several landslides due to high water levels. The worst one in 1955 killed 55 people and caused vast destruction of buildings and infrastructure. The local government departments and agencies in Lilla Edet had limited experience of working with climate change adaptation and this project was the first attempt to enable a discussion across sectors on these issues. The combination of climatic similarities and socio-economic differences between the municipalities make it rewarding to compare how local government officials perceive how socio-economic factors influence local vulnerability to flooding in the two development projects.

As presented above, both municipalities are currently working with a major development project. Both of these projects concern major establishment of settlements in areas prone to flooding. The project in Gothenburg involves the renewal of a centrally located area called Gullbergsvass, serving as one of the busiest communications hubs in Sweden. The area that today mostly consists of old industrial sites will, according to the plans, be 
transformed into an attractive housing, office and trade distinct. The project in Lilla Edet involves the development of a residential area, called Södra Lödöse, which will be located near a newly constructed railway station. The National Railroad Agency decision to localise the train station in the municipality will significantly improve the ability to commute to Gothenburg. The project, hence, creates an opportunity to establish a new urban centre close to the station to attract new citizens by providing attractive and affordable municipal services and housing. The new railway station also improves the commuting opportunity tremendously by reducing the travel time to Gothenburg from more than one hour to less than thirty minutes.

Swedish municipalities are described as having a monopoly on physical planning and the local planners often describe themselves as particularly fit to balance environmental, economic and social objectives in their everyday practices (Storbjörk 2007; von Borgstede and Lundqvist 2006). This motivates why it was decided to concentrate this study on local government officials. In each of the cases, a group of officials was established, consisting of officials from municipal departments together with regional offices of national authorities (Table 1 below). This setup was chosen to capture a great range of views on the part of individual municipal officials and organisational cultures as well as to capture the many ways in which socio-economic and climate change inflict on local municipal operations.

[Insert table 1 about here] 


\subsection{Data Collection}

The data used in this study was collected between 2007 and 2010. It consists of notes from seven short pilot interviews, transcripts from thirteen deeper semi-structured individual interviews with government officials and a one-hour group exercise conducted with each of the two groups of officials. Analyses of central municipal documents have also been carried out.

The pilot interviews aimed at providing an overview of how the organisations addressed climate vulnerability and adaptation and what the officials saw as the central documents. Respondents from the major technical infrastructure departments were interviewed. The deeper semi-structured interviews with government officials lasted about one hour and intended to identify challenges currently facing their own local government organisations. The seven respondents from Gothenburg represented: Physical planning, Environment, Traffic, Parks and nature, Energy, and Railroad administration. The six respondents from Lilla Edet represented: Physical planning, Environment, as well as Water and sanitation. When analysing the interview transcripts, both researchers read through them, indicating, first, the major challenges, second, to what extent the challenge was seen as climate-related and, third, to what climate or socio-economic stress the challenge was related. Results were compared, differences and similarities in the individual coding were discussed, and the challenges were grouped into wider stress categories. These categories formed a common base for the second round of analysis, in which both researchers grouped the challenges according to which of the exposure, 
sensitivity or adaptive capacity elements of integrated vulnerability it was primarily related by the respondents.

The group exercises aimed at enabling a systematic discussion of how socio-economic and climatic stresses interact to shape local vulnerability to flooding and how they relate to practical management within the local government organisations. The eight participants from Gothenburg and the six participants from Lilla Edet represented the organisations presented in table 1 above. Prior to the group exercise, participants were asked to individually rank a set of socio-economic factors according to how influential the respondent viewed it for local vulnerability to flooding in a questionnaire. These socio-economic factors included the stresses from the conceptual framework presented in table 2 and other potential stresses identified from national surveys (Holmberg and Weibull 2007). Based on the individual rankings of socio-economic factors, the two groups separately discussed differences and similarities in their responses. Participants were also asked to select the most critical stresses facing their own organisation in general and for the case in particular. Interview transcripts were analysed in a similar way as the individual interview transcripts.

\section{A conceptual framework for analysing socio-economic stress}

Integrated vulnerability studies are asking who, how, and why somebody is vulnerable.

They conceive vulnerability of systems as partly determined by exogenous change and

physical risks, partly on the localization and quality of the socio-technical infrastructure

(Leichenko and O'Brien 2002; Eakin 2005). In other words, they use the integrated

vulnerability perspective to analyse, firstly, how a system is exposed to existing and 
future climatic stress such as changes is temperatures, precipitation and sea water levels, as well as socio-economic stress. Secondly, they analyse how sensitive the system is to the changes brought about by the climatic and socio-economic stress. Thirdly, the capacity of the system to adapt to these stresses is analysed. Several studies with an explicit aim of analysing the integrated influence of socio-economic and climatic stress on a system's vulnerability have gone under the name of "Double Exposure" (e.g. O’Brien and Leichenko 2000; Leichenko and O'Brien 2008). The Double Exposure framework was elaborated to capture the 'rapid, on-going economic and institutional changes' that are 'exposing many rural regions to the impacts of globalization and climate change, with new sets of winners and losers emerging in the process' (Leichenko and O'Brien, 2002, p. 3). These approaches are analysing two challenges facing local managers: first, it incorporates more than one stress at a time (O'Brien et al. 2004); second, it synthesizes impacts occurring at different administrative, spatial, and temporal scales (Adger et al. 2005; Eakin et al. 2009). In this section the major ways in which these studies have demonstrated that socio-economic stress interact with climatic stress in shaping local vulnerability is presented.

The socio-economic stresses analysed in the Double Exposure studies referred to either economic globalization specifically or non-climatic stress more generally. In all studies examined, the authors decided on a case-by-case basis what specific socio-economic stresses to include. The socio-economic stress studied was described as highly dramatic. It had also occurred in the past, but its repercussions were still impinging on local activities and action. For example, study addressed the agricultural sector after 
liberalization, i.e., major institutional change involving increased export competition and implementation of macroeconomic programmes (Eakin 2005). The Double Exposure studies did not only address sectors that had undergone drastic socio-economic change, but they also focused on social groups or sub-sectors that were assumed to be relatively more sensitive to the changing socio-economic conditions. Consequently, the studies focussed on what were ex ante hypothesized to be relatively vulnerable units. This focus on particularly vulnerable units is important to bear in mind when applying the framework to other social contexts.

Table 2 contains those socio-economic stresses that were most prominently seen to interact with climate variation and change to shape local vulnerability in the studies examined. This list is used as a conceptual framework in this study by deciding what stresses to focus on in the two cases. Below follows a description of how these stressors were seen to shape local vulnerability in the literature examined.

[Insert table 2 about here]

Economic globalization is seen to change relative prices by affecting input costs as a consequence of market enlargement (e.g. Belliveau et al. 2006). The cost difference between domestic and foreign production is argued to increase significantly and to create incentives for relocation (Keskitalo 2008a). The impacts of changing relative prices were seen to be unevenly distributed across spatial and social strata (O'Brien and Leichenko 2000; Eakin 2005; 2009). The Double Exposure studies examined have also 
demonstrated an increasing pressure on private actors to provide access to credit and insurance schemes. This privatization of credit and risk spreading is, consequently, reducing reliance on government-provided schemes (O’Brien and Leichenko 2003; O'Brien et al. 2004; Eakin 2005). The private creditors generally favour larger production units, enhancing the pressure to grow (Eakin 2005; Keskitalo 2008a). It also fuels increased mechanization, which requires capital and, accordingly, increases the exposure to interest rate fluctuation (Leichenko and O’Brien 2002; Eakin 2005). It may thereby influence vulnerability by affecting the ability to invest and to insure buildings and infrastructure against e.g. flooding. Fierce foreign competition was also conceived as an impact of globalization that influences local vulnerability by potentially affecting budgets and by putting pressure on organizations to be more attractive (Leichenko and O’Brien 2002; O’Brien et al. 2004; Keskitalo 2008a; Eakin 2009). Economic globalization gives foreign producers access to the domestic markets simultaneously as it provides domestic producers access to substantially larger markets. The changed extent of the market puts pressure on the degree of specialization, favouring organizations and human agents that are already running highly productive operations. This suggests that the productivity of an activity could serve as an indicator of sensitivity. Less productivity indicates higher sensitivity to import competition and vice versa (O'Brien et al. 2004). Highly productive systems could, however, also be sensitive because they become less flexible for changes. Double Exposure studies have also uplifted the significance of market structure. Rules for market or retail access and the composition of actors have a direct effect on vulnerability (Belliveau et al. 2006; Kestitalo 2008a; 2008b). Changing rules that are affecting marked structure and access challenge the current industrial 
structure, resulting in frequent changes in ownership, mergers, etc. (Eakin 2005;

Keskitalo 2008a), and creating new climate exposures for some producers (Belliveau et al. 2006). The Double exposure studies recorded a positive effect in terms of access to technical options to adapt to climate change, e.g. access to drought-resistant cultivars or irrigation (Leichenko and O'Brien 2002; O'Brien et al. 2004). However, the access to technical options was seen to be primarily determined by ability to pay (Leichenko and O’Brien 2002; Belliveau et al. 2006). Technical change could also be associated with failure, implying that new technologies may create new sensitivities or exposures (Belliveau et al. 2006). Finally, externalisation of policy change was explained to shape local vulnerability by increasing the exposure of local communities to remote political decisions that act as a spark that sets the social change in motion (e.g. Leichenko and O’Brien 2002).

\section{Results}

The conceptual framework (Table 2) above was used to discuss how socio-economic stresses were seen to interact with climatic stresses to shape local vulnerability to flooding in the two cases. From the collected data it was clear that exposure, sensitivity and adaptive capacity each provided an avenue for analysis, guiding the presentation of the analysed empirical material below.

\subsection{Creating new and shifting 'old' local exposures}

Respondents demonstrated that socio-economic change shaped local vulnerability to flooding by creating new and shifting 'old' exposures. We found that exposure was 
acting in two principal ways by: affecting the respondents' worldviews and aggravating the current exposure of floods.

Firstly, the socio-economic stress affected Gothenburg and Lilla Edet comprehensively by shaping the respondents' worldviews and, consequently, the political goals that the local governments set out to realize. In Gothenburg, the project aims at creating a compact 'regional core', i.e. a more metropolitan-like area of which Gullbergsvass area will be key. Establishing a regional core was seen as a response to the self-assessed critical stress exerted by fierce foreign competition and poorer economic growth prospects due to a changing market structure. For example, the recent financial crisis demonstrated the exposure of the region to shifts on the global vehicle market. The core, thus, was deemed necessary to continue to attract highly skilled people and new investment. It, thus, explains the local emphasis on attractive housing and regional growth, aiming at increasing the productivity of activity. As one Gothenburg respondent stated:

"This with regionalising is quite interesting since the growth document which the Region Association has produced is about building very much in the centre of Gothenburg, which is low areas, to make the region competitive in the future"

The respondents in Lilla Edet pointed out the need to adapt to a stronger perceived intermunicipality competition, especially between the major Swedish regions Stockholm, 
Gothenburg and Malmo-Copenhagen. The project is intended to create incentives to become part of a larger region in response to both changes in market structure and fierce foreign competition. Previously, the municipality was primarily exposed to local employers, one of which is a major transnational company that could well relocate its activities. A Lilla Edet respondent explained the relationship with the employer:

“... Lilla Edet have since long back in time put trust in the big employers to be there for us, Virtually all who wanted to work was able to get a job there. But they have stopped hiring today, and it constantly shrinks, when they are investing the number of employed are decreasing"

By improving possibilities to commute, the ambition is to provide stronger incentives for citizens to stay in the municipality, regardless if the big employer were to relocate. The intention is also to attract new citizens with significantly lower housing prices than in the regional core. In the future, respondents saw Lilla Edet as primarily exposed to the overall regional employment trends, characterized by vehicle manufacturing and an advanced service and knowledge sector in Gothenburg. Interestingly, respondentsfrom both municipalities described a 'regionalized' future in which the two project areas played important but quite distinct roles.

Secondly, establishing a regional core will likely increase real estate values significantly in both municipalities. Localization of more buildings and infrastructure close to the large river Göta älv will aggravate the current level of exposure to flooding in these 
areas. To varying degrees, the respondents were critical to localize more buildings and infrastructure to these areas, especially in the Gothenburg case, since the area has frequently experienced floods due to weather variability. The respondents rather proposed to move such facilities away from the flood-prone area, but recognised that this option was limited by the political goal of establishing a regional core. The respondents also to some extent identified the handling of liability claims as a problem, linking the discussion to privatization of risk spreading. Insurance aspects, though, are clearly related to vulnerability to floods because Swedish municipalities, as water and sewerage operators, are responsible for damage caused by deficient pipes and could be held liable for physical plans, which was noted in the Lilla Edet case.

\subsection{Shaping local sensitivity}

Sensitivity to flooding was a frequent topic in both the individual interviews and group discussions. Both projects aspire to locate more buildings, infrastructure, economic activity and people in the climatically exposed case areas. In Gothenburg the densification of Gullbergsvass is aggravating sensitivity and the consequences of a flood by increasing the sheer number of buildings, infrastructure, people, and level of economic activity in the area. As indicated by a Gothenburg respondent this effect is inevitable if the area is to be developed:

"If you are going to develop this area, then the buildings have to be quite tall, since there have to be such high levels of exploitation to reach an economic bearing...." 
In the Gothenburg case, respondents clearly viewed the current degree of sensitivity to flooding as a good indicator of its future sensitivity. That is, if the objects already are sensitive, time will aggravate this, without further measures. Officials pointed out that the general velocity of social and economic change - regardless of its direction - has increased significantly over the last decade. This rapidness in change was seen as requiring more flexibility in planning and in the adaptive responses instigated. Yet, as explained by several respondents, the decision to compact buildings and infrastructure in the project areas is working counter to such flexibility. As stated by a Gothenburg respondent:
"You know Gothenburg builds itself into a dead end, once one have built houses under water level one has taken on a long term commitment to make sure the houses can be there"..."One can never back out and say let's quit repairing our barriers...”

The traffic system in Gothenburg is already operating close to maximum capacity. Any deviation from normal procedure is difficult to accommodate. Operating close to maximum capacity was by some respondents seen as a promising indicator of system sensitivity and, thus, could serve a similar function as productivity. In Gothenburg, serious problems in road traffic, regardless of increased investment up to 2030, were anticipated in the Gullbergsvass area. The plan is also to expand public transportation, which should be seen in the light of existing high flood exposure via car tunnels, power facilities, and, especially, the location of main train station. Respondents here illustrated 
how the ability to counteract trends of increasing traffic is limited by an overall political objective to of a centralized traffic system. This political objective constrains the ability to re-locate parts of the traffic infrastructure. The issue at hand then becomes how to counteract the increased amount of infrastructure by adaptive, reactive responses to limit the overall vulnerability to flooding. In Gothenburg, each department had mapped how its technical system within the Gullbergsvass area could be impacted by flooding in the future. These mappings covered individual objects, technical systems and specific areas with high risk of flooding. It did not, however, cover how social and economic activity and people would be directly affected by flooding or by system failure. In the individual interviews, the respondents generally expressed high belief in technical advances to reduce sensitivity (c.f. Glaas et al. 2010). According to previous literature, however, such new access to technical options can contribute to either reducing or increasing sensitivity. Negative aspects of new technology were not directly expressed in Gothenburg.

In Lilla Edet sensitivity was viewed as impossible to determine in Södra Lödöse because of the uncertainty and large degree of freedom in choosing what will be located there. Rather, sensitivity was viewed as being shaped by the areas that already are exposed to flooding (especially in spring). Locating housing and logistics in these areas was seen as unwise and limitations in planning of, for instance, water and sewerage might affect drainage capacity since the whole area could not be drained at once. Consequently, areas adjacent to the new settlement will be flooded, according to the respondents.

Respondents also perceived that the future sensitivity of the area in Lilla Edet was 
primarily determined by the most critical parts of the socio-technical infrastructure: sewerage and drainage, which was caused by both high current sensitivity and high public costs of extending the system to the new residential area. Respondents gave several concrete examples of how the infrastructure systems are currently being affected by flooding. Following statement was made by a Lilla Edet respondent when discussing system sensitivity:

"In terms of robust systems it is what we do not have"..."we have very fragile systems and they get more and more fragile and are of course more affected by changes in climate, wind, water and everything"

Low infrastructure system robustness was also perceived by other respondents in Lilla Edet, for example for water and sanitation systems and car tunnels. Respondents noted a general trend towards less staff working with operation and maintenance of these infrastructure systems. This is an example of how changing relative prices continuously put pressure on the most expensive production factor, in this case labour. Lower funds, in relative terms, for maintenance were also increasing system sensitivity to flooding. The respondents noted a lack of knowledge of system sensitivity at the political level, but were confident in the ability of the system managers to identify the most sensitive parts of their systems.

\subsection{Shaping local adaptive capacity}

Among all respondents adaptive capacity was seen to be influenced by socio-economic stress, both internally and externally. By internally we mean something within the 
mandate of the local government organizations themselves, while externally refers to stresses driven by exogenous processes.

Examples of internal factors identified by the respondents were: lack of expertise to assess climate change risks (Lilla Edet), lack of expertise to evaluate climate adaptation measures (both municipalities), insufficient knowledge of the local hydrological cycle (Gothenburg), unclear division of responsibility between municipal departments and between public and private actors (both municipalities), and limited financial resources (both municipalities, but with very large variation between departments in Gothenburg). The internal factors were partly explained by changes in market structure and fierce foreign competition decreasing departments' available funds. But also by the fact that the climate adaptation issue itself were seen as a fairly new topic on the municipal agenda.

Examples of external factors identified by the respondents include unclear legal liability (both municipalities), inadequate institutional structure (Lilla Edet), bumpy national taxes and support (both municipalities), expensive climate impact support material (both municipalities), and unclear division of costs between municipalities and national agencies (both municipalities). These were explained by an absence of external policy change guiding climate adaptation. Respondents viewed this lack of regulation as creating a situation where it is up to the individual organizations themselves to decide whether or not they address climate change. Nevertheless, the organizations are often not given extra funds for that purpose. 
Unclear division of responsibility between hierarchal levels was seen as a significant component of vulnerability to flooding in Gothenburg. Thus by clarifying the roles of various actors in flood response would likely reduce overall vulnerability. This is an example of the significance of rules prescribing how local government actors should interact with other public and private actors. For example, possible costs of adapting the technical infrastructure have been mapped by the local government departments in Gothenburg. However, how to share the cost of these measures has not yet been determined and is seen as a 'hot potato'. Generally, the respondents also observed that the ability to adapt Gullbergsvass to a changing climate depends on a stable economic situation in the municipality and a reliable division of funds between the various sectors. Economic activity is seen to increase through the Gullbergsvass development, not only by enlarging the total volume but also by increasing the share of high-value-added activities. However, the respondents were quite sceptical that this will guarantee more funds devoted to climate adaptation of the infrastructure. One Gothenburg respondent claimed:
"Well there is an over-confidence that the exploitation will provide funds for infrastructure which I do not think it will because of the geotechnical instability, high water levels and polluted soil..."

This view was partly shared but less emphasized by the Lilla Edet respondents. The anticipated larger economic resources will, according to the respondents, affect public revenues and spending and might, although not necessarily, end up as funds devoted for 
climate adaptation. If the climate adaptation funds increase, respondents observe, so will the local ability to reduce vulnerability to flooding. Respondents are sceptical, however, and note that they are not counting their chickens until they hatch. As observed, socioeconomic stresses can quickly and drastically change the present state and cause a redirection of municipal funds to other sectors, directly affecting adaptive capacity. One Lilla Edet respondent exemplified how increasing costs of social services triggered a budget cut for the environment department. As explained by a respondent:

“...to enforce our readiness, a wise planning ... and engagement from municipal officials is needed. If these ... [funds] are used by problems within the social administration then we have to lower our budget because theirs are increasing, and that is exactly what we see this year. We had a budget and we have a plan to implement, for example, preventive measures..."

Funding scarcity is forming a large part of the identified problems in Lilla Edet. But unclear division of responsibility between departments was also viewed as a problem that specifically affected the local officials. If the departments differ in their approaches and only see issues from their own sector's perspective, activities requiring collaboration fall through the cracks. Due to tight budgets, competition rather than collaboration is occurring between the departments.

This problem was also emphasised by respondents in Gothenburg. As argued, funding competition is leading to a mind-set of officials focused on becoming a winning 
department rather than on providing the best possible services and adaptive response. A Gothenburg respondent notes:

"Take the exploitation along the Göta älv banks as example, the real estate office and [a building company] runs it and all of the municipal departments are to get their needs considered. That is huge transfers of funds in a huge process were everyone is terrified of getting stuck with "the joker" in the end, were you get cost but not getting them covered in the exploitation"

Departmental competition risks creating a situation in which proactive actions, such as climate adaptation, are ignored in light of more acute issues. This departmental competition thus encourages adaptive measures with a low degree of common benefits, and, thus, specific technical fixes become the focus rather than addressing climate adaptation more holistically.

\section{Discussion}

Both cases revealed that socio-economic stress was not systematically included in the local risk-based analyse of vulnerability to flooding. Nevertheless, the discussions demonstrated that such factors were clearly seen to shape local vulnerability. This section discusses what socio-economic stresses were perceived to be the most critical in shaping local vulnerability to flooding, what specific elements of integrated vulnerability were influenced by the socio-economic stress in the two cases, and how can climatic and socio-economic stress be more efficiently managed within local government organisations. 


\subsection{Most critical socio-economic stresses}

Results revealed that some socio-economic stresses were more critical in shaping local vulnerability to flooding than others. The two most apparent stresses were fierce foreign competition and market structure which acts as shaping the worldview within the local communities. Fierce foreign competition served as a raison d'être for undertaking these projects by re-orienting current economic structure away from the perceived fierce competition. The projects can also been seen as adaptations to changes in market structure experienced during the last decades. The worldviews and goals presented by the respondents facilitate understanding why the decisions to carry out the projects were made. Neither project was initiated as a climate adaptation project; instead, they were adaptations to perceived socio-economic stress with climate adaptation as an 'add-on'. Climate change was first discussed after the decision already had been taken at a higher political level, without much reflection of climate change, vulnerability to flooding or practical management aspects.

Even if not as central, all stresses identified in the conceptual framework were conceived as more or less important in shaping local vulnerability to flooding. In our application, changing relative prices were seen to result in reducing the employment for operation and maintenance of the technical infrastructure systems. In this context, it is important in shaping vulnerability, but it was more difficult to point out more exactly how it will play out in the future. Productivity was seen as negatively shaping vulnerability to flooding by putting more pressure on infrastructure systems which already operate close to maximum capacity. Externalisation of policy change was seen as necessary to guide 
local action in a specific context rather than a factor influencing local management. In that sense it was not policy change, but rather an absence of policy on climate adaptation and flooding that was seen influencing vulnerability. Generally, the respondents paid less attention to externalisation of policy change at the EU and national levels than to other socio-economic stresses. Privatization of risk spreading and insurance was not addressed to a great extent within the case study. Insurance aspects are clearly related to vulnerability to floods in Sweden since municipalities, as water and sewerage operators, are responsible for damage caused by deficient pipes and could be held liable for physical plans. Last, access to technical options was not so apparent in our study. When discussed respondents generally expressed high believes in the possibilities of technical advances for decreasing vulnerability. Negative effects of new technology were generally less expressed.

\subsection{Influences on vulnerability to flooding}

In this study we have used the concept of integrated vulnerability which principally can be influenced in three ways, by effecting exposure, sensitivity and/or adaptive capacity. In the two cases, socio-economic stress was seen to influence these components in slightly different ways.

[Insert table 3 about here]

As presented in table 3 above, all components of vulnerability were seen to be influenced by socio-economic stress in the two municipalities, both positively and negatively. It became obvious that it officials found it easy to analyze the influences on sensitivity and 
exposure, but much harder to analyze influences on adaptive capacity. This is well in line with e.g. Belliveau et al (2006) and Keskitalo (2008a) who argue that the involvement of stakeholders and practitioners is particularly useful when it comes to sensitivity issues because of their detailed knowledge of how the system currently operates. However, sensitivity was restricted to impact on the technical infrastructure in both municipalities, not to the activities they sustain. The views on how adaptive capacity is perceived and the own ability to affect it diverged more significantly between the municipalities. Adaptive capacity signifies what can be done to counteract impacts and is related to the status of the socio-economic structure, and thereby resources available for climate adaptation measures. The Lilla Edet respondents believed more in high future economic development which can explain the differences between the municipalities. But the study also illuminated large differences in the ability to respond between the municipal departments. Different conceptions of who is primarily responsible for these issues emphasize the necessity of clearly addressing division of responsibility and the role of local government. More frequent floods and the need for adaptation highlight the unclear responsibility division between government departments.

\subsection{Evolving local climate adaptation strategies}

Based on the results, we propose two general approaches to how climatic and socioeconomic stress can be more efficiently incorporated into adaptive planning in the studied municipalities. Though ultimate effectiveness of adaptation are argued difficult to determine (e.g. Preston et al 2010), our suggestions proposes changes in the long term planning processes of adaptation strategies. 
Firstly, this study revealed a high level of knowledge of the sensitivity of the technical systems, but markedly less knowledge of how technical system failure affects social and economic activity, also experienced in other Swedish municipalities (e.g. Johansson et al. 2006). Consequently, local vulnerability assessments are often focused on analysing sensitivities of existing technical systems in specific areas. To be able to incorporate influences of socio-economic and climatic stress, the focus of assessments should be shifted towards future sensitivity of people and settlements in a planned area. This facilitates its use in comprehensive planning. Here much could be learned from the use of scenarios (c.f. Tompkins et al. 2008) in environmental impact assessments. Involving citizens and businesses would also likely add two important dimensions to assessments: how economic and social activity is affected and consequences of failing systems. By using such stakeholder involvement, and new approaches to assessing vulnerability, it is further likely that alternatives to the adaptation measures focused on barriers and drainage/pumping will be found. This can help increase the flexibility in adaptation planning demanded by respondents in this study.

Secondly, the cases demonstrated that vulnerability to flooding was constructed in hindsight. It is left to officials, engineers, etc. to analyse vulnerability and take action in an ad-hoc manner. Accordingly, adaptive planning has so far been made in temporary and spatially delimited projects after the major political decisions already had been taken A challenge is, thus, to orient vulnerability management towards processes rather than projects to create better opportunities for addressing the issue continuously. In creating long term strategies, municipalities can learn much from local and regional strategic 
planning for economic growth. Both growth and vulnerability are insufficient to approach as a one-time issue due to their dynamic and rapid characteristics (Glaas et al. 2010; Storbjörk 2010). Contrary to vulnerability, growth is rarely dealt as a one-time issue. Instead, local and regional economic strategies are periodically revised. Vulnerability would be more adequately managed if it were approached in a similar way. Much would be accomplished by 'mainstreaming' climate adaptation into long-term strategic planning. As a first step could potential influences of both socio-economic and climatic stress on vulnerability to flooding be incorporated in the municipalities' master plans. Here could the conceptual framework be used as a basis for such discussions.

\section{Conclusions}

This study have analysed how socio-economic stress influence local vulnerability to flooding in two local cases in Swedish municipalities, and how such stress can be more efficiently managed by evolving local adaptation strategies. A conceptual framework consisting of potential stresses was applied to development projects in two municipalities, using transcripts from interviews and group exercises with officials from local government departments and local offices of national government agencies. The results revealed that the two most significant socio-economic stresses were fierce foreign competition and market structure which acts as shaping the worldview within the local societies. Fierce foreign competition served as a raison d'être for undertaking the projects at all by re-orienting current economic structure away from international and national economic competition. The projects can also been seen as adaptations to market structure changes during the last decades. Further, all components of integrated vulnerability -exposure, sensitivity, and adaptive capacity - were seen to be influenced by 
socio-economic stress, both positively and negatively. Officials were skilled in analyzing influences on sensitivity and exposure, but found it harder to analyze influences on adaptive capacity. Sensitivity was seen influenced in similar ways within the municipalities, but were only related to technical infrastructure, not to the activities they sustain. Views on how adaptive capacity is influenced by socio-economic change diverged more significantly, both between municipalities and between municipal departments. An unclear responsibility division between departments partly explains this diffusion.

This article proposes two general approaches to how climatic and socio-economic stress can be more efficiently incorporated in local management. Firstly, shifting focus of local vulnerability assessments towards future sensitivity of people and settlements in planned areas would facilitate incorporation of influences of climatic and socio-economic stress and the use of assessments in comprehensive planning. Here much could be learned from the use of scenarios within environmental impact assessments and involvement of citizens and businesses in adaptive planning. Second, by 'mainstreaming' climate adaptation into long-term strategic planning vulnerability would be addressed as a dynamic issue to be periodically revised. As a first step influences of socio-economic and climatic could stress be incorporated in municipalities' master plans. Here the conceptual framework could be used to start such discussions.

However, more research is required to build a more thorough understanding of how to move from analysing climate change risks to assessing and managing integrated 
vulnerability in various cases. An interesting research question examined here is how to develop practical methods that take account of wider stakeholder perspectives.

\section{Acknowledgements}

This study was funded by the Swedish Research Council for Environment, Agricultural Sciences and Spatial Planning (Formas), Grant 250-2006-2234, 'Enhancing municipalities' capacity to manage climate change' and the project 'Baltic Challenges and Chances for local and regional development generated by Climate Change BalticClimate' funded by the European Regional Development Fund of the Baltic Sea Region Programme. We are also grateful to K. André for carrying out the pilot interviews, to A. Jonsson, Y. Andersson-Sköld, and L. Simonsson for participating in the project, and to the anonymous reviewers and S. Storbjörk for their valuable comments and Proper English for their careful editing and linguistic help.

\section{References}

Adger N (2006) Vulnerability. Glob Env Change 16:268-281

Adger N, Agrawala S, Mirza M et al (2007) Assessment of adaptation practices, options, constraints and capacity. In: Parry, M Canziani, O Palutikof, J et al (eds) Climate Change 2007: Impacts, Adaptation and Vulnerability, Contribution of WG II to the Fourth Assessment Report of the Intergovernmental Panel on Climate Change. Cambridge University Press, Cambridge, pp 717-743

Adger N, Arnell N, Tompkins E (2005) Successful adaptation to climate change across scales. Glob Env Change 15:77-86

Adger N, Vincent K (2005) Uncertainty in adaptive capacity. Comptes Rendus Geosci $337: 399-410$ 
Ahmad I (2009) Climate Policy Integration: Towards Operationalization, DESA Working paper No. 73, United Nations, New York

Alveson M (2002) Understanding organizational culture. Sage, London

Andersson-Sköld Y, Fallsvik J, Hultén C et al (2008) Climate change in Sweden geotechnical and contaminated land consequences. In: A De Santis et al (eds)

Conference proceedings, WSEAS international conference on environmental and geological science, 11-13 September 2008, Malta: WSEAS Press, pp 52-57

Belliveau S, Smit B, Bradshaw B (2006) Multiple exposures and dynamic vulnerability: evidence from the grape industry in the Okanagan Valley, Canada. Glob Env Change $16: 364-378$

Biesbroek R, Swart R, Carter T et al (2010) Europe adapts to climate change: Comparing National Adaptation Strategies. Glob Env Change 20:440-450

Bouwer L, Bubeck P, Aerts J (2010) Changes in future flood risk due to climate and development in a Dutch polder area. Glob Env Change 20:463-471

Eakin H (2005) Institutional change, climate risk, and rural vulnerability: cases from Central Mexico. World Dev 33:1923-1938

Eakin H, Winkels A, Sendzimir J (2009) Nested vulnerability: exploring cross-scale linkages and vulnerability teleconnections in Mexican and Vietnamese coffee systems. Env Sci \& Policy 12:398-412

Füssel H-M, Klein R (2006) Climate change vulnerability assessments: an evolution of conceptual thinking. Clim Change 75:301-329

Gallopin G (2006) Linkages between vulnerability, resilience, and adaptive capacity. Glob Env Change 16:293-303 
Glaas E, Andersson-Sköld Y, Hjerpe M et al (2010) Managing climate change vulnerabilities: formal institutions and knowledge use as determinants of adaptive capacity at the local level in Sweden. Local Env 15:525-539

Gothenburg municipality (2006) Extreme weather events - how robust is Gothenburg, Göteborg stadskansli, Gothenburg

Gothenburg municipality (2009) Extreme weather events phase 2, Göteborg stadskansli, Gothenburg

Holmberg S, Weibull L (eds) (2007) Svenska trender 1986-2006, SOM Institute, Gothenburg University

Huq S, Reid H (2004) Mainstreaming adaptation in development. IDS Bulletin 35:15-21

Johansson A, Svedung I, Andersson R (2006) Management of risks in societal planningan analysis of scope and variety of health, safety and security issues in municipality plan documents Safety Sci 44:657-688

Keskitalo C (2008a) Vulnerability and Adaptive Capacity in Forestry in Northern Europe: The Case of Sweden. Clim Change 87:219-234

Keskitalo C (2008b) Climate Change and Globalization in the Arctic: An Integrated Approach to Vulnerability Assessment. Earthscan, London

Leichenko R, O'Brien K (2002) The dynamics of rural vulnerability to global change: the case of southern Africa. Miti and Ad Strat for Glob Change 7:1-18

Leichenko R, O’Brien K (2008) Environmental Change and Globalization: Double Exposures. Oxford University Press, Oxford

Næss L-O, Bang G, Eriksen S et al (2005) Institutional adaptation to climate change: flood responses at the municipal level in Norway. Glob Env Change 15:125-138 
O’Brien K, Hochachka G (2010) Integral adaptation to climate change. J of Integral Theory and Practice 5:89-102

O’Brien K, Leichenko R (2000) Double exposure: assessing the impacts of climate change within the context of economic globalization. Glob Env Change 10:221-232

O’Brien K, Leichenko R (2003) Winners and Losers in the Context of Climate Change Ann of the Assoc of Am Geogr 93:89-103

O’Brien K, Leichenko R, Kelkar U et al (2004) Mapping vulnerability to multiple stressors: climate change and globalization in India. Glob Env Change 14:303-313

Preston B, Westaway R, Yuen, E (2010) Climate adaptation planning in practice: an evaluation of adaptation plans from three developed nations. Mitig Adapt Strateg Glob Change 16:407-438

Statistics Sweden (2010) Tabeller över Sveriges befolkning, Statistics Sweden, Stockholm

Storbjörk S (2007) Governing climate adaptation in the local arena: challenges of risk management and planning in Sweden. Local Env 12:457-469

Storbjörk S (2010) It takes more to get a ship to change course: barriers for organizational learning and local climate adaptation in Sweden. J of Env Policy \& Plan 12:235-254

Swedish Government Official Reports (SOU) (2007) Sweden facing climate change: threats and opportunities, SOU 2007:60. Ministry of the Environment/Commission on Climate and Vulnerability, Stockholm 
Tompkins E, Few R, Brown K (2008) Scenario-based stakeholder engagement: incorporating stakeholders preferences into costal planning for climate change. $\mathrm{J}$ of Env Man 88:1580-1592

Urwin K, Jordan A (2007) Does public policy support or undermine climate change adaptation? Exploring policy interplay across different scales of governance. Glob Env Change 18 180-191

von Borgstede C, Lundqvist L (2006) Organizational culture, professional role conceptions and local Swedish decision-makers' views on climate policy instruments. J of Env Policy \& Plan 8:279-292 
Table 1. Municipal departments and regional offices of national authorities participating in the groups

\begin{tabular}{ll}
\hline Gothenburg & Lilla Edet \\
\hline Physical planning & Physical planning \\
Environment & Environment \\
Traffic & Technical \\
Water and sanitation company & Water and sanitation \\
Parks and nature & \\
Energy company & \\
Railroads (regional office) & \\
\hline
\end{tabular}


Table 2. Conceptual framework for analysis of socio-economic stress

Changing relative prices

Privatization of credit and risk spreading

Fierce foreign competition

Productivity

Changing market structure

Access to technical options

Externalisation of policy change 
Table 3. Influences of socio-economic change on local vulnerability to flooding

\begin{tabular}{lll}
\hline & Gothenburg & Lilla Edet \\
\hline Exposure & - More compact city closer to the & - New developments on low lying \\
& river & ground \\
\hline Sensitivity & - More pressure on already sensitive & - Lower budgets for system \\
& infrastructure & maintenance \\
& - More robust technical systems & - More pressure on sewerage \\
& - Lower flexibility in adaptive & systems \\
& planning & \\
\hline Adaptive & - Increased departmental & - More funds available for adaptive \\
Capacity & competition leading to measures & planning \\
& with less common benefits & \\
\hline
\end{tabular}

